\title{
Miniaturized MPA with Asymmetric Z-Shaped CSRR Loading
}

\section{Mansi, Praveen Kumar Chakravarti}

\begin{abstract}
The work in the paper demonstrates a rectangular microstrip patch antenna with a Z-shaped CSRR loading in the ground plane. A Z-shaped CSRR created in the ground plane, shown a $63.3 \%$ miniaturization in the radiating patch size compared to conventional rectangular patch antenna, resonating at $6.5 \mathrm{GHz}$ frequency in $\mathrm{C}$-band. The simulation results find a significant increase in the fractional bandwidth $(5.54 \%$, with the centre frequency of $6.5 \mathrm{GHz}$ ). Furthermore, the antenna has simulated gain of $2.83 \mathrm{~dB}$ and return loss of $-26.33 \mathrm{~dB}$ at $6.5 \mathrm{GHz}$. The electrical size of proposed antenna is $0.325 \lambda \mathrm{o} \times 0.260 \lambda \mathrm{o} \times$ $0.034 \lambda o$ (i.e., $15 \mathrm{~mm} \times 12 \mathrm{~mm} \times 1.6 \mathrm{~mm}$ ). The proposed antenna may find application in satellite communication systems in C-band and Wireless local area network (WLAN).
\end{abstract}

Keywords- Microstrip patch antenna (MPA), Complementary Split Ring Resonator (CSRR), Miniaturization, Fractional bandwidth.

\section{INTRODUCTION}

A most important application of microstrip patch antenna is in the field of satellite communication systems. Most of the satellite communication systems operate in the C-band of the electromagnetic spectrum. The antenna designed specifically for satellite communication systems is required to have large value of antenna fractional bandwidth and must have small dimensions. This paper presents an antenna having miniaturized dimensions and large bandwidth at $6.5 \mathrm{GHz}$ in comparison to the conventional patch antenna at same resonant frequency. Use of slotted ground structure or making defects in the ground plane of the patch antenna is a method, initially applied to get a reduction in the size of patch antenna [1]. Adding a defect in the ground plane couples a reactive circuit with the patch antenna which may subsequently results an increase in the electrical path length $[2,3]$. An increase in the electrical path length results in a decrease in the antenna physical dimensions. But this method of antenna miniaturization may also decrease the efficiency of the patch antenna. One new approach of miniaturization of patch antenna is the use of Complementary Split Ring Resonator (CSRR). These CSRRs reduce the size of the patch antenna without affecting the radiation characteristics. Number of research papers are available showing patch antenna design with CSRR in ground plane or in the patch [4-7]. Inclusion of split ring resonator in the patch antenna results in a decrease in the guide wavelength and subsequently the antenna physical dimensions [8].

Revised Manuscript Received on February 05, 2020.

Mansi, M. Tech. Student, Department of Electronics \& Communication, Meerut Institute of Engineering \& Technology, Meerut, Uttar Pradesh, India. E-mail: mansiecb1995@gmail.com

Praveen Kumar Chakravarti, Assistant professor, Meerut Institute of Engineering and Technology, Meerut, India. E-mail: praveen.chakravarti@miet.ac.in

(C) The Authors. Published by Blue Eyes Intelligence Engineering and Sciences Publication (BEIESP). This is an open access article under the CC BY-NC-ND license (http://creativecommons.org/licenses/by-nc-nd/4.0/)
* Correspondence Author

In this research paper, a rectangular microstrip patch antenna fed with a inset microstrip line and having a Z-shaped CSRR in the ground plane is designed. The designed antenna is simulated with hfss v15 software and all radiation characteristics are drawn and attached with the paper. The CSRR used in the antenna is of asymmetric shape. The equivalent circuit of the CSRR is also explained in the paper. The results obtained by the simulation are discussed.

\section{ANTENNA GEOMETRY}

The geometric configuration of the proposed microstrip patch antenna with Z- shaped CSRR loading in the ground plane is shown in the figure 1 . The antenna is designed using an inexpensive FR4 epoxy glass substrate of thickness $1.6 \mathrm{~mm}$ having relative permittivity $\mathrm{\varepsilon r}=4.4$ and loss tangent $\tan \delta=0.02$. A Z- shaped CSRR is created by etching a $Z$-shape of fixed dimension in the ground plane and a rectangular radiating patch with inset feed is used as a radiating element. The dimensions of the proposed antenna are mentioned in table 1 .

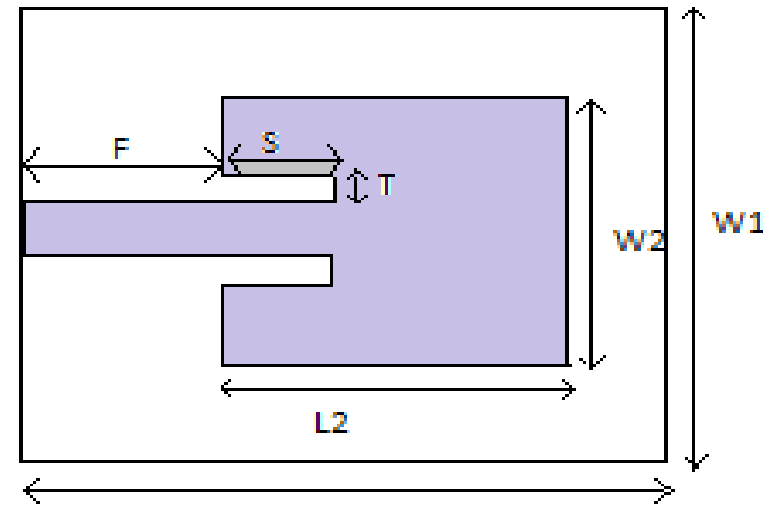

L1

(a)

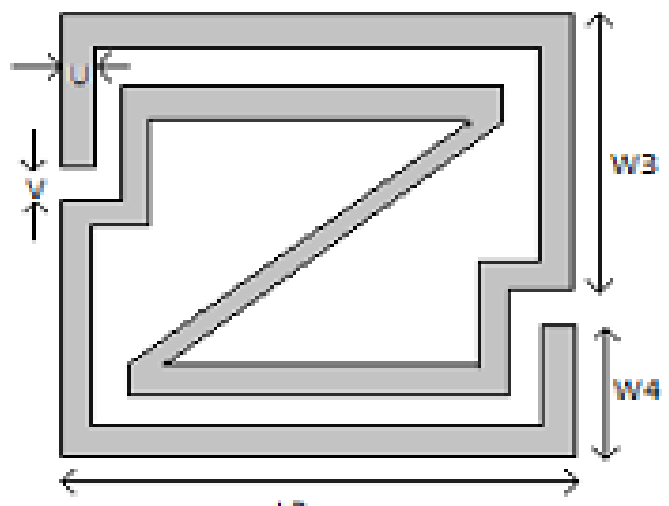

L3

(b) 


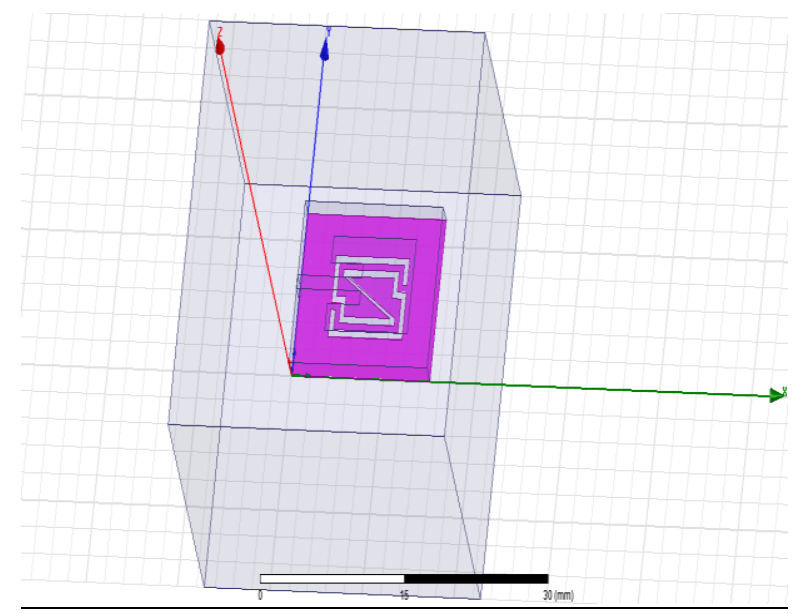

(c)

Figure 1. (a) top, (b) bottom and (c) hfss view of the proposed antenna

TABLE I. Physical dimensions of the patch antenna

\begin{tabular}{|c|c|c|c|}
\hline Parameter & $\begin{array}{c}\text { Unit } \\
(\mathbf{m m})\end{array}$ & Parameter & $\begin{array}{c}\text { Unit } \\
(\mathbf{m m})\end{array}$ \\
\hline L1 & 15 & F & 3.5 \\
\hline W1 & 12 & L3 & 8 \\
\hline L2 & 9 & W3 & 4 \\
\hline W2 & 7 & W4 & 1.5 \\
\hline S & 3.5 & U & 0.5 \\
\hline T & 1 & V & 0.5 \\
\hline
\end{tabular}

$\mathrm{S}$ and $\mathrm{F}$ that defines the inset feed connection are chosen in such a way that the feed and the radiating patch have impedance matching. Other dimension of the patch antenna are the dimensions after miniaturization.

\section{EQUIVALENT CIRCUIT OF THE PROPOSED Z-SHAPED CSRR UNIT CELL}

Figure 2 shows the equivalent circuit model of Z-shaped CSRR [9]. The proposed Z-shaped structure consists of a inductive-capacitive resonance circuit.

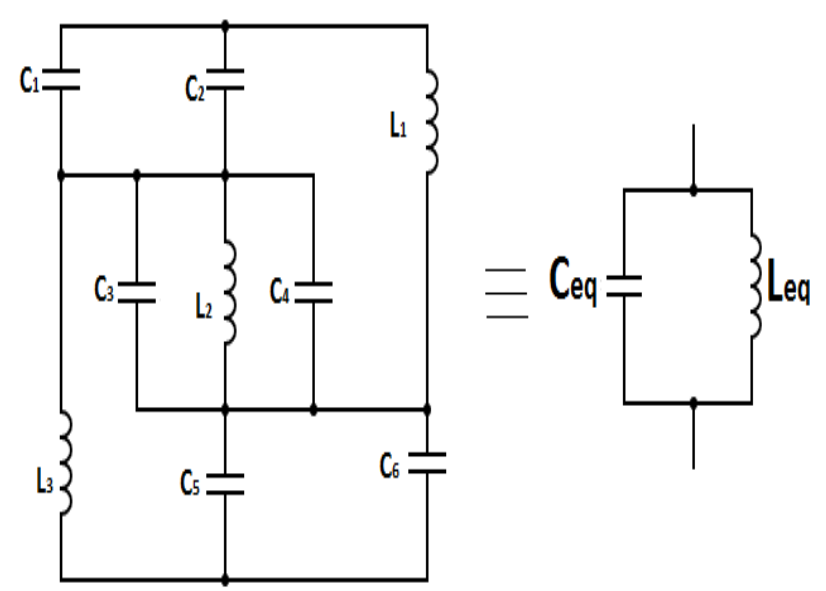

Figure 2. Equivalent circuit of proposed Z-shaped CSRR
The resonant frequency (fr) can be written as,

$$
f=\frac{1}{2 \pi \sqrt{\text { Leq. Ceq }}}
$$

where $\mathrm{L}$ and $\mathrm{C}$ represents the equivalent inductance and capacitance of the proposed Z-shaped CSRR equivalent circuit.

The structure etched in the ground plane is equivalent to a metal strip folded in $\mathrm{Z}$ shape and placed on a dielectric substrate. This circuit behaves like a inductive capacitive circuit. Fringes that reach the ground plane from dielectric in the form of surface waves result in electric and magnetic resonance condition.

$\mathrm{C} 1, \mathrm{C} 2, \mathrm{C} 3$, C4 and C5 are the capacitance values due the splits and L1, L2 and L3 are the inductances due to the metal strip as shown in the equivalent circuit.

\section{RESULTS, DISCUSSIONS AND ANALYSIS}

4.1 Return loss- The plot of parameter s11 which is also called as Return loss is depicted in the figure 3 . This plot demonstrate the impedance matching condition for the designed patch antenna. The C-band resonant frequency of the miniaturized antenna is $6.5 \mathrm{GHz}$ and the return loss is $-26.33 \mathrm{~dB}$ at this resonant frequency. The fractional bandwidth of the proposed antenna is $5.54 \%$ (with centre frequency of $6.5 \mathrm{GHz}$ ).

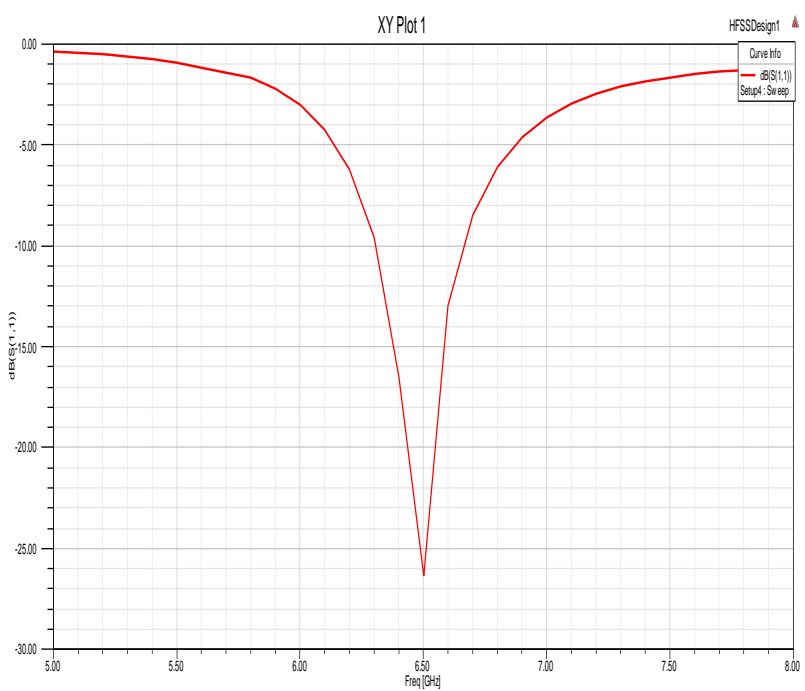

Figure 3. Return loss plot of the proposed antenna

4.2 Gain and Directivity- The antenna proposed in the paper gives a positive gain value at its resonant frequency. The peak value of gain for the miniaturized antenna is $2.83 \mathrm{~dB}$ and its directivity at same resonant frequency is $3.96 \mathrm{~dB}$. 


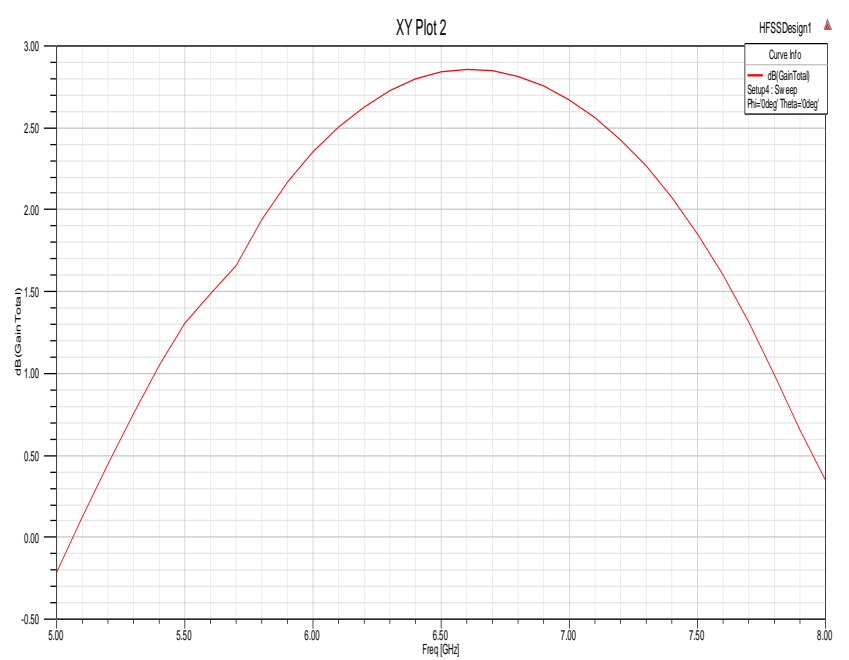

Figure 4. Gain vs frequency plot of the proposed antenna

4.3 Radiation Pattern- Radiation pattern of an antenna can be drawn as a $2 \mathrm{D}$ radiation plot or as a $3 \mathrm{D}$ polar plot. Both of these plot shows the radiation direction and direction of maximum radiation for a designed antenna. The plot in the figure 5 shows the semi-omnidirectional pattern which is good for satellite communication systems.

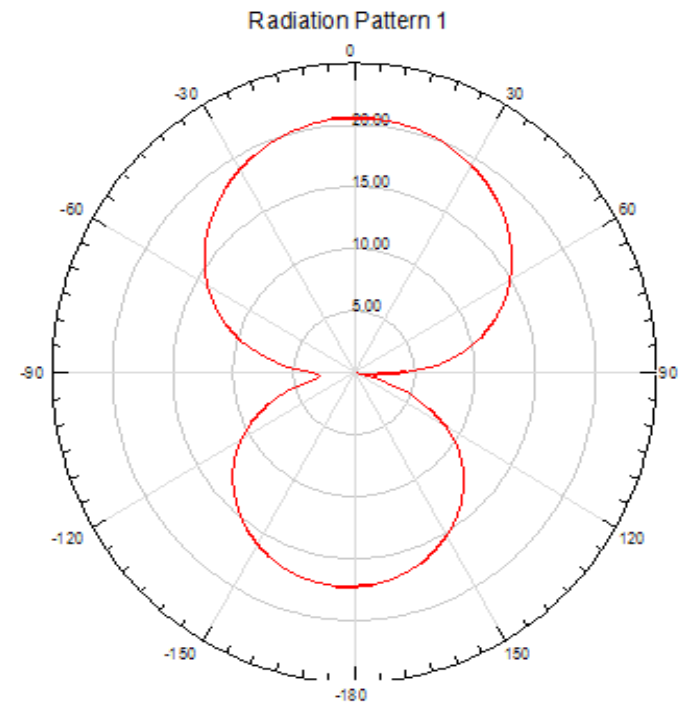

(a)

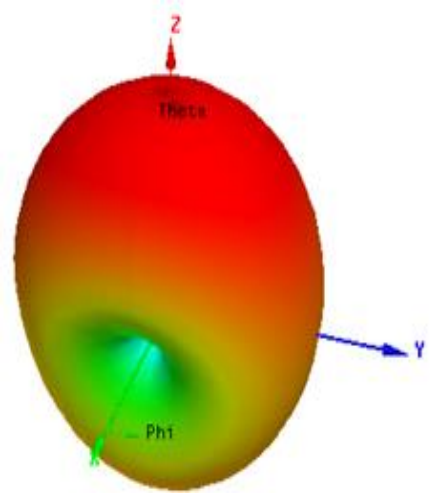

(b)

Figure 5 (a) 2D Radiation Pattern, (b) 3D Polar plot of the proposed antenna at $6.5 \mathrm{GHz}$

4.4 Antenna Efficiency- Efficiency of an antenna defines the ability of antenna to radiate. Proposed antenna results a good radiation efficiency of $77 \%$.

4.5 Field distributions- Figure draws the E-field distributions and the H-field distributions for the patch and proposed Z-shaped CSRR.

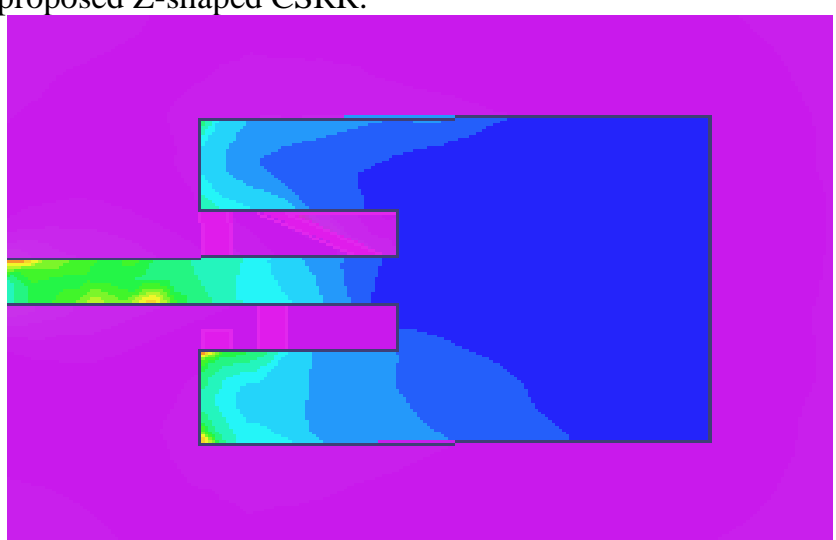

(a)

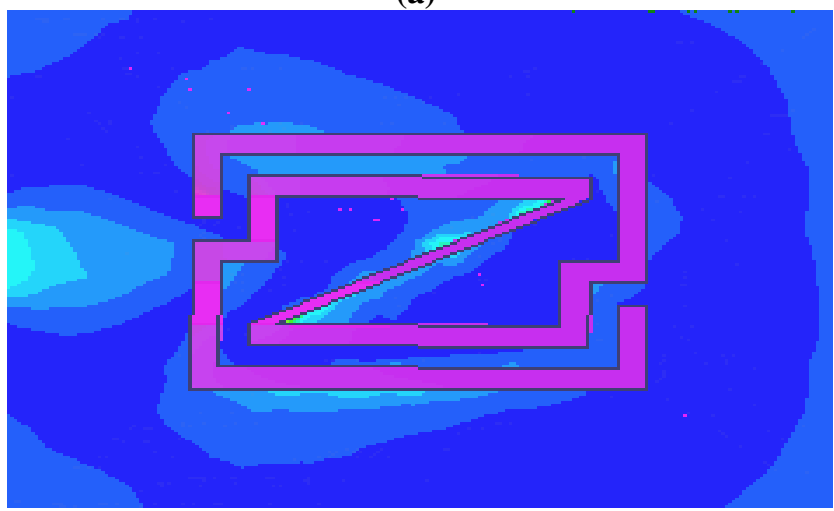

(b)

Figure 6. E-field distribution of (a) rectangular patch, (b) Z-shaped CSRR in ground plane.

4.6 Co-Polarisation and Cross-Polarisation- Plots of both the polarizations are drawn in terms of a rectangular graph. A table is also drawn showing the maximum and minimum values of both the polarization components.

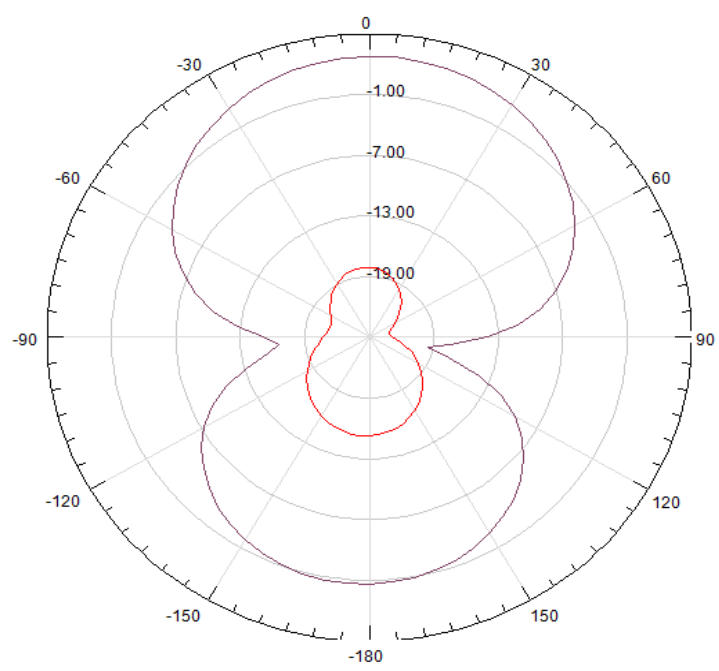

(a) 


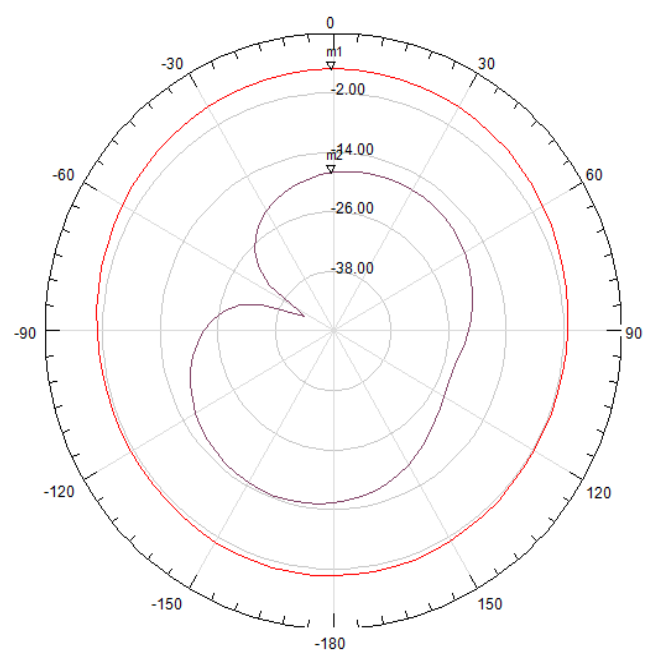

(b)

Figure 8. (a) E-Plane Co-polarisation and Cross-polarisation, (b) H-Plane Co-polarisation and Cross-polarisation

TABLE II. Co-Polarisation and Cross-Polarisation

\begin{tabular}{|c|c|c|}
\hline Plane & Max. Co-pol.(dB) & $\begin{array}{c}\text { Max. } \\
\text { Cross-pol.(dB) }\end{array}$ \\
\hline E-Plane & 2.80 & -18.05 \\
\hline H-plane & 2.80 & -18.05 \\
\hline
\end{tabular}

4.7 Voltage Standing Wave Ratio (VSWR)- Antenna's impedance matching characteristic is measured using the parameter VSWR. The simulation result gives the VSWR to be 1.10. So, it can be said that the proposed antenna is matched with the feed source.

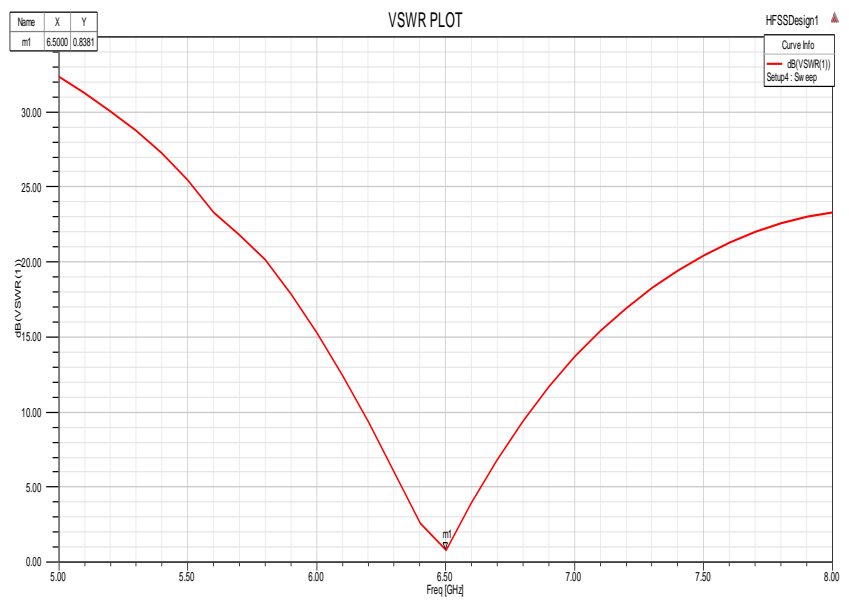

Figure 9. VSWR vs Frequency plot of the proposed antenna at $6.5 \mathrm{GHz}$

4.8 Miniaturization- The effective area of the conventional patch antenna at resonant frequency of $6.5 \mathrm{GHz}$ is about $518 \mathrm{~mm}^{2}$ whereas the effective area of the proposed antenna for the same resonant frequency is $180 \mathrm{~mm}^{2}$. The proposed antenna results in $63.30 \%$ reduction in radiating patch size whereas $65.25 \%$ reduction in overall antenna size. Table 3 gives a comparison between the dimensions of patch for conventional patch antenna and that of the proposed antenna.

TABLE III. Comparison between the conventional patch dimensions and proposed antenna patch dimensions

\begin{tabular}{|c|c|c|c|c|c|}
\hline Antenna & $\begin{array}{l}\text { Freq. } \\
\text { (GHz) }\end{array}$ & $\begin{array}{l}\text { Patch } \\
\text { length } \\
, \mathrm{L} \\
(\mathrm{mm}) \\
\end{array}$ & $\begin{array}{c}\text { Patch } \\
\text { Width,W(m } \\
\text { m) }\end{array}$ & $\begin{array}{l}\text { Patch } \\
\text { Area, } \\
\left(\mathrm{mm}^{2}\right)\end{array}$ & $\begin{array}{c}\text { Electrical } \\
\text { size of whole } \\
\text { antenna }\end{array}$ \\
\hline $\begin{array}{l}\text { Patch } \\
\text { without } \\
\text { CSRR } \\
\end{array}$ & 6.5 & 11.3 & 15.2 & 172 & $\begin{array}{l}0.244 \lambda \mathrm{o} \times 0.3 \\
29 \lambda_{0} \times \\
0.034 \lambda_{0}\end{array}$ \\
\hline $\begin{array}{l}\text { Patch } \\
\text { with } \\
\text { CSRR } \\
\text { (Z-shape } \\
\text { d) }\end{array}$ & 6.5 & 9 & 7 & 63 & $\begin{array}{l}0.325 \lambda_{0} \times 0.2 \\
60 \lambda_{0} \times \\
0.034 \lambda_{0}\end{array}$ \\
\hline
\end{tabular}

\section{CONCLUSION}

A microstrip patch antenna with Z-shaped CSRR loading in the ground plane is designed and simulated using hfss v15 software. The results and figures obtained by simulating this antenna are attached in the paper and discussed as well. The antenna results in very good radiation characteristics and designed in compact size. The fractional bandwidth of the antenna is $5.54 \%$ which is quite good in case of a patch antenna. This antenna find its application in the C-band which is reserved for satellite and wireless communication applications. This antenna can be further improved by using CSRR arrays in the ground plane.

\section{REFERENCES}

1. Y. Dong, H. Toyao and Tatsuo Itoh "Design and characterization of miniaturized patch antennas loaded with complementary split-ring resonators," IEEE Transactions on antennas and propagation, vol. 60, no. 2, pp.772-785, Feb 2012.

2. S Maci, B Biffi Gentili, P Piazzesi, and C Salvador "Dual-band slot loaded patch antenna" ,IEEE Proc.-Microw.Ant. Propag. 1995;142:225-232.

3. Xie Y H, C. Zhu, L. Li, C. H. Liang, "A novel dual-band metamaterial antenna based on complementary split ring resonators," Microw. Opt. Technol. Lett. 2012; 54:1007-1009.

4. Ashish Gupta, Sameer K. Sharma, and Raghvendra K. Chaudhary "A compact dual-mode metamaterial-inspired antenna using rectangular type CSRR" , Progress in Electromagnetics Research C, Vol. 57, 35-42, 2015.

5. H. Mosallaei and K. Sarabandi, "Antenna miniaturization and bandwidth enhancement using a reactive impedance substrate," IEEE Trans. Antennas Propagat., vol. 52, no. 9, pp. 2403-2414, Sept. 2004.

6. Nornikman Hassan, Badrul Hisham Ahmad, Mohamad Zoinol Abidin Abd Aziz, Zahriladha Zakaria, Mohd Azlishah Othman, Abdul Rani Othman, Kamaruzaman Jusoff and Zanariah Jano, (2013) "Microstrip Patch Antenna with a Complementary Unit of Rhombic Split Ring Resonator (R-SRR) Structure" World Applied Sciences Journal 21(Special Issue of Engineering and Technology): 85-90.

7. Y. Lee, and H. Yang, "Characterization of microstrip patch antennas on metamaterial substrates loaded with complementary split-ring resonators," Microw. Opt. Tech. Lett. 2008; 50:2131-2135.

8. Ricardo Marqués, Member, IEEE, Francisco Mesa, Member, IEEE, Jesús Martel, and Francisco Medina, Senior Member, IEEE, "Comparative Analysis of Edge- and Broadside- Coupled Split Ring Resonators for Metamaterial Design-Theory and Experiments", IEEE Trans. Antennas Propag, vol. 51, no. 10, 2003.

9. Md. Mehedi hasan, Mohammad Rashed Iqbal Faruque, Sikder Sunbeam Iqbal and Mohammad Tariqul Islam “ A new compact double negative

miniaturized metamaterial for wideband operations," Materials 2016,9(10),830. 
10. V. Rajeshkumar, S. Raghavan "A compact CSRR loaded dual band microstrip patch antenna for wireless applications," 2013 IEEE International Conference on Computational Intelligence and Computing Research, 978-1-4799-1579-2.

11. Yoonjae Lee, Simon Tse, Yang Hao, and Clive G. Parini "A compact microstrip antenna with improved bandwidth using CSRR loading," IEEE 1-1244-0878-4/07,2007.

12. Bhavna Thakur, Ashwini Kunte "Compact dual-band patch antenna using triangular complementary split ring resonators for WiMax/WLAN," 2018 International Conference on Communication, Information \& Computing Technology (ICCICT), Feb. 2-3, Mumbai, India.

13. Bhavna Thakur, Ashwini Kunte "Compact dual band patch antenna using meandered complementary split ring resonators," $20183^{\text {rd }}$ International Conference for Convergence in Technology (I2CT) , Pune, India,Apr 06-08,2018.

\section{AUTHORS PROFILE}

Mansi, M.Tech. Student, Department of Electronics \& Communication, Meerut Institute of Engineering \& Technology, Meerut, Uttar Pradesh, India. She has completed her B.Tech. from Meerut Institute of Engineering \& Technology, Meerut in 2017. Her area of interest is Antenna \& its applications in wireless technologies. Her research work includes the designing of Rectangular Microstrip Patch Antennas for Satellite and Radar applications.

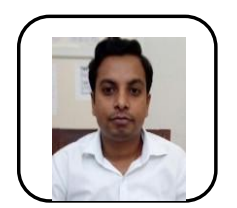

Praveen Kumar Chakravarti, received the B.Tech degree in Electronics and Communication Engineering from UPTU, Lucknow in 2008 and did his M.E. in Electronics and Communication Engineering from NITTTR (Punjab University) Chandigarh. He worked as a Lecturer in Sachdeva Institute of Technology, Mathura. Praveen Kumar Chakravarti has more than 7 research papers published in International Journals and Conferences in the fields of Wireless Communications, Signal Processing and Antenna Design. He joined Meerut Institute of Engineering and Technology, Meerut in July 2012 and is currently serving as Assistant professor in Meerut Institute of Engineering and Technology, Meerut . 